\title{
ПЛ-7 \\ ИСТОРИЯ РАЗВИТИЯ И СОВРЕМЕННЫЕ ВОЗМОЖНОСТИ МЕТОДА АЭС-ИСП
}

\author{
Бухбиндер Г.Л.
}

Представительство Intertech Trading Corporation в Красноярске, Красноярск, Россия

glb@intertech-corp.ru

DOI: 10.26902/ASFE-11_08

Атомно-эмиссионная спектрометрия (АЭС) с индуктивно связанной плазмой (ИСП) одно из самых важных и самых ярких достижений аналитической химии XX века. Уникальный комплекс достоинств метода позволил занять ведущее место в элементном анализе самых разнообразных материалов.

К концу 50-х - началу 60-х годов XX века потенциал основных источников возбуждения спектра - дуги и искры, был исчерпан. Начался активный поиск новых источников, которые могли улучшить метрологические характеристики атомноспектральных методов анализа. В 1964-1965 году были опубликованы работы Гринфилда (Великобритания), Боуманса (Голландия), Фассела (США) о возможности применения ИСП атомной спектрометрии в качестве источника возбуждения. Первые коммерческие спектрометры для реализации метода АЭС-ИСП были выпущены компаниями Jarrell Ash (CШA) и ARL (Швейцария) в 1974 году. Основными типами спектрометров были 20-40 канальные полихроматоры или сканирующие монохроматоры с ФЭУ, основной вид обзора плазмы - радиальный, положение горелки - вертикальное. В 1980-х годах началось внедрение метода в промышленность и для контроля экологической обстановки, появились стандартизованные методики анализа воды, цветных и черных металлов. Количество производителей оборудования значительно расширилось.

Пять революционных изменений в конструкции спектрометров: горизонтальное расположение горелки, аксиальный обзор плазмы, двойной (аксиальный и радиальный) обзор плазмы, регистрация спектров полупроводниковыми детекторами, полностью полупроводниковые, без генераторной лампы, экономичные генераторы, - существенно изменили рынок коммерческих спектрометров в начале 1990 -х годов. Не все производители сумели внедрить новейшие технологии, значительная часть заводов постепенно закрыла производство эмиссионных спектрометров с ИСП.

С технической точки зрения современный эмиссионный спектрометр с ИСП - это прибор с одновременной регистрацией всего спектра на полупроводниковом детекторе, с двойным (аксиальным и радиальным) обзором плазмы, с горизонтальным или вертикальным расположением горелки, полупроводниковым генератором с эффективностью передачи энергии в плазменный разряд на уровне 80-90\%. За счет такой эффективности максимальная потребляемая мощность спектрометров снизилась до уровня 2,5-3 кВт и позволяет подключить их к обычной электрической розетке 220B, 16А.

Для измерения доступны линии 78 определяемых элементов в диапазоне от 130 до 900 нм. Большинство производителей игнорируют диапазон 130-167 нм, в котором находятся достаточно чувствительные линии хлора и брома, считая, что рынок спектрометров в этой области достаточно узкий, и что эти элементы лучше определять с использованием метода ионной хроматографии. Поэтому усложнение и удорожание конструкции приборов для работы в диапазоне 130-167 нм не имеет большого коммерческого смысла.

Лучшие коммерческие эмиссионные спектрометры с ИСП позволяют определять не менее 70 элементов с пределами обнаружения не более 1 мкг/дм ${ }^{3}$ и активно вытесняют из лабораторий атомно-абсорбционные спектрометры с пламенной и электротермической атомизацией, особенно в тех случаях, когда требуется одновременный многоэлементный анализ.

Благодаря градуировке по отношениям концентраций и градуировке способом ограничивающих стандартов АЭС-ИСП позволяет определять основные компоненты металлов, сплавов, геологических и технических материалов с точностью сравнимой, а часто и превосходящей точность классических методов анализа: гравиметрии, титриметрии, пробирного анализа.

Дальнейшее развитие метода АЭС-ИСП можно ожидать на следующих направлениях:

- разработка плазменных горелок с пониженным потреблением аргона;

- расширение круга анализируемых материалов с использованием АЭС-ИСП; 
- поиск новых схем генерирования химических паров определяемых элементов с последующим вводом в ИСП; проб;

- разработка высокоэффективных схем прямого ввода в плазму жидких и твердых

- пересмотр стандартизованных методик анализа воды, почвы, нефтепродуктов, смазочных масел, они были созданы более 30 лет назад и не учитывают современные возможности АЭС-ИСП. 